Correspondence

Zhensheng Pan

zhensheng@gmail.com

Received 20 March 2009

Revised 22 June 2009

Accepted 25 June 2009

\section{Identification of genetic and phenotypic differences associated with prevalent and non-prevalent Salmonella Enteritidis phage types: analysis of variation in amino acid transport}

\author{
Zhensheng Pan, ${ }^{1,2}$ Ben Carter, ${ }^{1} \dagger$ Javier Núñez-García, ${ }^{1}$ Manal AbuOun, ${ }^{1}$ \\ María Fookes, ${ }^{3}$ Al Ivens, ${ }^{3} \ddagger$ Martin J. Woodward ${ }^{1}$ and Muna F. Anjum ${ }^{1}$ \\ ${ }^{1}$ Department of Food and Environmental Safety, Veterinary Laboratories Agency-Weybridge, New \\ Haw, Addlestone, Surrey KT15 3NB, UK \\ ${ }^{2}$ School of Biological Sciences, Royal Holloway, University of London, Egham, Surrey TW20 OEX, \\ UK \\ ${ }^{3}$ The Wellcome Trust Sanger Institute, Hinxton, Cambridge CB10 1SA, UK
}

\begin{abstract}
In this study, differences at the genetic level of 37 Salmonella Enteritidis strains from five phage types (PTs) were compared using comparative genomic hybridization $(\mathrm{CGH})$ to assess differences between PTs. There were approximately 400 genes that differentiated prevalent $(4,6,8$ and 13a) and sporadic (11) PTs, of which 35 were unique to prevalent PTs, including six plasmid-borne genes, pef $A, B, C, D, s r g C$ and $r c k$, and four chromosomal genes encoding putative amino acid transporters. Phenotype array studies also demonstrated that strains from prevalent PTs were less susceptible to urea stress and utilized L-histidine, L-glutamine, L-proline, L-aspartic acid, gly-asn and gly-gln more efficiently than PT11 strains. Complementation of a PT11 strain with the transporter genes from PT4 resulted in a significant increase in utilization of the amino acids and reduced susceptibility to urea stress. In epithelial cell association assays, PT11 strains were less invasive than other prevalent PTs. Most strains from prevalent PTs were better biofilm formers at $37{ }^{\circ} \mathrm{C}$ than at $28^{\circ} \mathrm{C}$, whilst the converse was true for PT11 strains. Collectively, the results indicate that genetic and corresponding phenotypic differences exist between strains of the prevalent PTs 4, 6, 8 and 13a and non-prevalent PT11 strains that are likely to provide a selective advantage for strains from the former PTs and could help them to enter the food chain and cause salmonellosis.
\end{abstract}

\section{INTRODUCTION}

Infection with nontyphoidal Salmonella (NTS) species is one of the leading causes of diarrhoea in developed

†Present address: Clinical Trials and Evaluation Unit, University of Bristol, Bristol Royal Infirmary, Bristol BS2 8HW, UK.

łPresent address: Fios Genomics Ltd, Edinburgh Technology Transfer Centre (ETTC), King's Buildings, Edinburgh EH9 3JL, UK.

Abbreviations: $\mathrm{AUC}$, area under the curve; $\mathrm{CGH}$, comparative genomic hybridization; MLST, multilocus sequence typing; PT, phage type.

The microarray data discussed in this paper are available from ArrayExpress under accession number E-MEXP-1720.

Eight supplementary tables, listing conserved and variant genes identified from $\mathrm{CHG}$ microarray of $28 \mathrm{~S}$. Enteritidis strains, genes identified to be unique in non-prevalent PT strains from CGH microarray, PCR validation of selected genes, MLST sequence types of 23 S. Enteritidis strains, and primers used in this study, are available with the online version of this paper. countries. Epidemiological studies have shown that relatively few Salmonella serovars/strains are responsible for the bulk of NTS infections in humans. In fact, serovars Enteritidis and Typhimurium are currently the most prevalent causes of human inflammatory gastroenteritis, often referred to as food poisoning (Gatto et al., 2006; Rodrigue et al., 1990). The current worldwide human epidemic of Salmonella Enteritidis is thought to have started in the 1980s, although some have suggested a much earlier date in the 1960 s after the introduction of $S$. Enteritidis into poultry flocks from rodents (Baumler et al., 2000). Irrespective of the exact starting point, the incidence of $S$. Enteritidis isolation from patients has increased dramatically since the 1980s (Ward et al., 2000). In 2007, a total of 155540 confirmed cases of human salmonellosis were reported in the European Union, with $64.5 \%$ of cases caused by S. Enteritidis (European Food Safety Authority, 2008). Increases in $S$. Enteritidis incidences were also reported in the USA starting from 1999, with more than 
1400 cases in 2006 (Centers for Disease Control and Prevention, Salmonella annual summaries; http://www. cdc.gov/ncidod/dbmd/phlisdata/salmonella.htm).

In 1987, a phage typing scheme for $S$. Enteritidis was described (Ward et al., 1987). The scheme is based on differences in susceptibility to a panel of reference bacteriophages that separates most $S$. Enteritidis phage types (PTs) into two distinct lineages, PT4-like strains (including PT1, PT4, PT4b, PT6, PT6a, PT7 and PT24) and PT8-like strains (including PT2, PT8, PT13, PT13a and PT23) (Guard-Petter, 1999). Recent studies have also revealed genomic differences between these two groups. Three prophage regions are mainly responsible for the difference, and include a $38 \mathrm{~kb}$ ST64B region, an $18 \mathrm{~kb}$ Fels-2 region and a few genes belonging to prophages ST27 and ST35 (Porwollik et al., 2005). Salmonella phage typing has become the recognized method by which epidemiologists attribute Salmonella outbreaks or epidemics to a specific strain type (Boccia et al., 2004; Lukinmaa et al., 2006; Usera et al., 1994). Within the last decade, $S$. Enteritidis PT4 and PT6 have been the most prevalent in Europe (Echeita et al., 2005; Gillespie et al., 2005), whereas in the USA and Canada, PT8 and PT13a are the most common types (Brown et al., 1999; White et al., 2007). In contrast, PTs such as PT11 have rarely been associated with human infection. Data from the UK Health Protection Agency (HPA) database show that over the past 10 years, $S$. Enteritidis human infections in the UK have mainly been due to PT4, PT6 and PT8 strains, which caused 40104 , 5804 and 5722 cases respectively, but only 916 cases were caused by PT11 isolates during the same time period (Christopher Lane, HPA Centre for Infections, personal communication). Also, a search within the Salmonella strain collection database at the UK Veterinary Laboratories Agencies (VLA) Enteric Reference Unit identified only 42 PT11 strains isolated in the past 10 years, in contrast to over 2000 PT4 strains isolated during this period from animals. However, it has been noted that different PTs become prominent at different times in a periodic manner. Therefore, the aim of this study was to analyse prevalent and sporadic/incidental strains from human infection within the Enteritidis serovar to gain insight into factors associated with epidemic strains prevalent in human infection.

We therefore chose a panel of $S$. Enteritidis strains from both prevalent and non-prevalent PTs $(4,6,8,13 \mathrm{a}$ and 11) gathered in the past 12 years to assess genomic differences by comparative genomic hybridization (CGH). A Salmonella pan-genome microarray covering seven Salmonella genomes (Cooke et al., 2007) was used for this study. We also characterized these strains using other approaches, such as multilocus sequence typing (MLST) and PFGE. Experiments to correlate phenotypic differences with genetic differences were also conducted in order to gain further insight into how genome variations contribute to the apparent differences in the prevalence of the various PTs.

\section{METHODS}

Bacterial strains, growth and DNA extraction. The bacterial strains used in this study (Table 1) included 42 human and animal isolates of Salmonella and seven sequenced laboratory strains [Salmonella bonogori 12419 (ATCC 43975), Salmonella Typhi CT18, Salmonella Typhimurium SL1344 (NCTC 13347), DT104 (NCTC 13348) and LT2 (ATCC 700220), Salmonella Gallinarum 287/91 (NCTC 13346), S. Enteritidis PT4 (NCTC 13349)]. Bacteria were cultured in Luria-Bertani (LB) broth overnight at $37^{\circ} \mathrm{C}$. Genomic DNA was extracted from overnight cultures using either a Qiagen Tissue DNA extraction kit or a Puregene kit (Gentra Systems) following the manufacturer's instructions.

Microarray experimental procedure. The design and construction of the pan-Salmonella array was an extension of a previous array (Thomson et al., 2004), incorporating specific genes found in newly sequenced Salmonella genomes (Cooke et al., 2007). For each strain, genomic DNA was extracted from at least two cultures grown independently. The genomic DNA from seven sequenced laboratory strains was mixed equally for the universal control mix (Cy5-labelled control channel), with each strain contributing a seventh (i.e. $0.286 \mu \mathrm{g})$ of the total DNA. The DNA $(2 \mu \mathrm{g})$ for every test strain was labelled with Cy3 dye (test channel). DNA labelling, hybridization and washing protocols were essentially performed as previously described (Wu et al., 2008). However, differences included resuspension of Cy3/Cy5-labelled DNA in a hybridization buffer composed of $5 \times$ SSC, $6 \times$ Denhardt's, $60 \mathrm{mM}$ Tris- $\mathrm{HCl}(\mathrm{pH} \mathrm{7.6)}$ and $0.12 \%$ Sarkosyl (Sigma, filter-sterilized), and the use of tRNA (from yeast, Sigma R8508) for blocking.

The microarray slides were scanned using the Genepix 4000B scanner (Axon Instruments). The images obtained were quantified with Genepix Pro software (Axon Instruments). Of the 12 strains from PT4, six strains $(4,5,6,47,48$ and 49) were tested in duplicate, while the rest (strains R2, R3, R5, R7, R8 and R9) were tested once due to the high consistency between results from strains in this phage group. At least two duplicate hybridization experiments were performed for the remaining test strains.

Normalization, analysis and validation of CGH microarrays. As described above, we produced CGH microarrays using an equal mix of genomic DNA from the seven sequenced Salmonella strains represented on the microarray (universal control) in the control channel. This enabled all spots present on the microarray to have a positive control following hybridization. We validated this novel approach of using a universal control by hybridizing genomic DNA from each sequenced strain in turn against the universal control. A collection of methods from the LIMMA package (Bioconductor; www.bioconductor.org) were applied to the microarray data (Supplementary Table S1). Present and absent/divergent genes for each method were selected using a threshold over the signal distribution, as described by Carter et al. (2008). Sensitivities and specificities for each normalization method were calculated by comparing the set of present and absent/divergent genes to the scores from BLASTN results of the PCR probe against the corresponding control sequenced strain. An illustration of this is given in Supplementary Table S1, which shows all sensitivities and specificities for all the normalization methods applied for strain SL1344. Supplementary Table S2 summarizes sensitivities and specificities for all seven sequenced strains using the two best-suited normalization methods. The best normalization method ( $\mathrm{Bc} 1$, median) was applied to all test strains.

PCR validation. PCR amplification was performed on selected genes present in the prevalent and non-prevalent PTs. All PCRs were conducted on a GeneAmp PCR System 9700 (Applied Biosystems) in 
Table 1. Bacterial strains used in this study

The strains were collected from different regional centres in the UK, both at the Health Protection Agency (HPA) and the Veterinary Laboratories Agency (VLA); source information has been given where available. NA, Not available.

\begin{tabular}{|c|c|c|c|c|c|}
\hline Strain & Serotype & PT & Source & Year & Host \\
\hline 01 & Enteritidis & PT13a & Coventry HPA & 1998 & Human \\
\hline 02 & Enteritidis & PT13a & USA & Unknown & Poultry \\
\hline 04 & Enteritidis & PT4 & Nottingham HPA & 1998 & Human \\
\hline 05 & Enteritidis & PT4 & Bristol Royal Infirmary & 1996 & Human \\
\hline 06 & Enteritidis & PT4 & UK & 1997 & Poultry \\
\hline 48 & Enteritidis & PT4 & Colindale HPA & 1997 & Human \\
\hline 51 & Enteritidis & PT4 & Colindale HPA & 1998 & Human \\
\hline $\mathrm{R} 2$ & Enteritidis & PT4 & Stonegate UK & 2002 & Poultry \\
\hline R3 & Enteritidis & PT4 & Humphrey, Wolfhanger UK & 2006 & Poultry \\
\hline R5 & Enteritidis & PT4 & Humphrey, Wolfhanger UK & 2003 & Poultry \\
\hline R7 & Enteritidis & PT4 & Cotswold House 8 UK & 2002 & Poultry \\
\hline 08 & Enteritidis & PT6 & Norwich HPA & 1995 & Human \\
\hline 09 & Enteritidis & PT6 & Birmingham Children's Hospital & 1996 & Human \\
\hline 10 & Enteritidis & PT8 & UK & 1996 & Poultry \\
\hline 11 & Enteritidis & PT8 & USA & 1999 & Egg \\
\hline 12 & Enteritidis & PT8 & St James's University Hospital, Leeds & 1998 & Human \\
\hline 41 & Enteritidis & PT11 & Colindale HPA & 1995 & Human \\
\hline 42 & Enteritidis & PT11 & Colindale HPA & 1995 & Human \\
\hline 43 & Enteritidis & PT11 & Colindale HPA & 1996 & Human \\
\hline 44 & Enteritidis & PT11 & Colindale HPA & 1996 & Human \\
\hline 45 & Enteritidis & PT11 & Colindale HPA & 2000 & Human \\
\hline 46 & Enteritidis & PT11 & Colindale HPA & 2000 & Human \\
\hline PE1 & Enteritidis & PT11 & VLA Weybridge & 2006 & Canine \\
\hline PE31 & Enteritidis & PT11 & VLA Weybridge & 1998 & Other animals \\
\hline PE33 & Enteritidis & PT11 & VLA Weybridge & 2007 & Cattle \\
\hline S13 & Enteritidis & PT3 & VLA Weybridge & 2008 & Dog \\
\hline L364 & Enteritidis & PT12 & VLA Weybridge & 2009 & Cat \\
\hline S6198 & Enteritidis & PT12 & VLA Weybridge & 2008 & Chicken \\
\hline S6236 & Enteritidis & PT12 & VLA Weybridge & 2008 & Chicken \\
\hline S475 & Enteritidis & PT22 & VLA Weybridge & 2008 & Chicken \\
\hline PT4 (NCTC 13349) & Enteritidis & PT4 & Sanger Centre, UK & $\mathrm{NA}$ & Sequenced laboratory strain \\
\hline LT2 (ATCC 700220) & Typhimurium & NA & Sanger Centre, UK & NA & Sequenced laboratory strain \\
\hline SL1344 (NCTC 13347) & Typhimurium & $\mathrm{NA}$ & Sanger Centre, UK & $\mathrm{NA}$ & Sequenced laboratory strain \\
\hline DT104 (NCTC 13348) & Typhimurium & DT104 & Sanger Centre, UK & $\mathrm{NA}$ & Sequenced laboratory strain \\
\hline $\begin{array}{l}\text { S. Gallinarum 287/91 } \\
\text { (NCTC 13346) }\end{array}$ & Gallinarum & NA & Sanger Centre, UK & NA & Sequenced laboratory strain \\
\hline CT18 & Typhi & NA & Sanger Centre, UK & NA & Sequenced laboratory strain \\
\hline $\begin{array}{l}\text { S. bongori } 12419 \\
\text { (ATCC 43975) }\end{array}$ & Bongori & NA & Sanger Centre, UK & NA & Sequenced laboratory strain \\
\hline
\end{tabular}


a total volume of $20 \mu \mathrm{l}$ with final concentrations of $1.5 \mathrm{mM} \mathrm{MgCl} 2$ and $200 \mu \mathrm{M}$ each dNTP, $1.0 \mathrm{U}$ Taq DNA polymerase and $10 \mathrm{ng}$ template DNA (HotStarTaq Plus Master Mix kit, Qiagen). The thermal cycling conditions were as follows: an initial denaturation at $95{ }^{\circ} \mathrm{C}$ for $10 \mathrm{~min}$, followed by 30 cycles at $95{ }^{\circ} \mathrm{C}$ for $30 \mathrm{~s}$, Tm for $45 \mathrm{~s}$ and $72{ }^{\circ} \mathrm{C}$ for $1 \mathrm{~min}$, completed by a final extension for $10 \mathrm{~min}$ at $72{ }^{\circ} \mathrm{C}$. The presence of PCR amplicons was examined by electrophoresis on a $1.5 \%$ agarose gel along with a $100 \mathrm{bp}$ and a $1 \mathrm{~kb}$ DNA Ladder (Promega) as markers. Primers used and annealing temperatures are listed in Supplementary Table S3).

MLST. Seven housekeeping genes were amplified using the protocols at the MLST database at the Enviromental Research Institute, University College Cork (http://mlst.ucc.ie/). The genes amplified were: thrA, purE, sucA, hisD, aroC, hemD and dnaN. The PCR products were purified using a QIAquick PCR Purification kit (Qiagen) and both strands were sequenced. The Lasergene v6 (DNASTAR, Inc.) software was used to align and analyse sequences. Allelic profiles and sequence type (ST) designations were assigned using the MLST database (http://mlst.ucc.ie/).

Adhesion and invasion assay. Strains $1,2,3,4,5,7,8,9,11,10$, $12,42,43,45,47,48$ and 51 (Table 1), and the sequenced laboratory strain PT4, which represented five PTs, were selected for adhesion and invasion assay. The standard protocol was followed as previously described (Dibb-Fuller et al., 1999). Bacterial cultures grown overnight at $37{ }^{\circ} \mathrm{C}$ in $\mathrm{LB}$ under aerobic conditions were centrifuged and the pellet was resuspended in pre-warmed Eagle's modified essential medium (EMEM; Sigma) supplemented with $1 \%$ L-glutamine (Sigma) and $1 \%$ non-essential amino acids (Sigma). The culture was adjusted to $10^{8}$ c.f.u. $\mathrm{ml}^{-1}$. Duplicate plates of $10-$ day-old Caco-2 human intestinal epithelial cells (well differentiated) were set up for association assays with bacterial cultures (Bolton et al., 2000). Adhesion and invasion assays were performed in four replicates per strain and repeated at least two times. The mean for each strain was calculated and strains representing each PT were grouped and compared. For statistical analyses, counts were $\log _{10^{-}}$ transformed and following a standard $\mathrm{F}$ test, a two-tailed $t$ test was carried out.

Biofilm forming assay and colony morphology. The ability of strains to form biofilms was assessed according to Woodward et al. (2000). Plates were read at $570 \mathrm{~nm}$ using an MRX Revelation absorbance reader (DYNEX, Magellan Biosciences). Blank values were obtained from wells that contained medium alone. The biofilm assay for each strain at each condition was performed at least twice with four technical repeats. Colony morphology and Congo red binding were analysed essentially as described previously (Allen-Vercoe et al., 1997). Congo red binding was observed when colonies developed a deep red colour within $\sim 72 \mathrm{~h}$ incubation.

Phenotype microarray and bacterial growth kinetics. Strains were grown on $\mathrm{LB}$ agar plates at $37{ }^{\circ} \mathrm{C}$ for $18 \mathrm{~h}$. To prepare the inoculum, colonies from each strain were suspended in medium base IF-0A (Biolog) and the turbidity was adjusted to $85 \%$. For PM3, the medium base was supplemented with $20 \mathrm{mM}$ sodium succinate, $2 \mu \mathrm{M}$ ferric citrate and $2.5 \mathrm{mg}$ thiamine $\mathrm{ml}^{-1}$. Each well of the Biolog plates was inoculated with $100 \mu \mathrm{l}$ inoculum of each strain. Tetrazolium violet was used as a redox dye to indicate via cell respiration the utilization of nutrient or biochemicals in plates. Cell respiration actively reduces tetrazolium dye and produces a strong purple colour. Plates were incubated at $37{ }^{\circ} \mathrm{C}$ for $48 \mathrm{~h}$. Phenotypic data were recorded with an OmniLog instrument, which captures a digital image of the plates every $15 \mathrm{~min}$, and colour change values were quantified. Kinetic data were analysed with OmniLog-PM software. Kinetic graphs were plotted by timescale and colour changes. The area under the curve (AUC) was calculated to assess substrate utilization by each strain. At least two individual repeats were performed for each strain.

Bacterial growth kinetics were monitored by using a FLUOstar OPTIMA plate reader (BMG Labtech). Strains were grown in $3 \mathrm{ml} \mathrm{LB}$ broth at $37^{\circ} \mathrm{C}$ for $16-18 \mathrm{~h}$. Bacterial cultures were inoculated into 96-well Iwaki plates to a final concentration that was $0.1 \%$ of the original inoculum. Each strain was tested in triplicate under each condition. Control medium (no bacteria) was also tested in triplicate. The plate was then incubated in the FLUOstar OPTIMA at $37^{\circ} \mathrm{C}$ for the desired time period. $\mathrm{OD}_{600}$ was measured and saved every $15 \mathrm{~min}$. M9 minimal medium with $1 \mathrm{mM}$ proline as sole nitrogen source was used for the proline utilization test. LB-G broth containing $3 \%$ urea was used for the urea stress test. At least three biological repeats were performed for each strain. The AUC was calculated and a two-tailed $t$ test was carried out to assess the statistical significance.

Inactivation of amino acid transporter genes and complementation. A knockout mutant of genes SEN1417-1420 in the sequenced PT4 strain (NCTC 13349) was constructed by insertional inactivation using the method of Datsenko \& Wanner (2000). Essentially, the gene region of interest (SEN1417-1420) was disrupted by inserting a kanamycin-resistance gene, thus preventing the gene from functioning (Fig. 4a). The kanamycin-resistance gene was PCRamplified with primers containing a $40 \mathrm{bp}$ region homologous to the target gene. The amplified kanamycin-resistance gene was transferred into the wild-type PT4 strain with a temperature-sensitive helper plasmid pKD46. The helper plasmid promoted homologous recombination between the kanamycin-resistance gene and the target gene. Chromosomal allelic exchange between the wild-type and the mutant copy then resulted in an isogenic mutant. The helper plasmid was then eliminated by increasing cultivation temperature to $37^{\circ} \mathrm{C}$.

In order to validate knockout mutants, primers from both outside and inside the knockout region were designed. Primers specific to helper plasmid pKD46 were also used to verify the elimination of the plasmid. PCRs were performed as described above. Primers used and annealing temperatures are listed in Supplementary Table S3. CGH was also used to validate the mutant strain. The same CGH slide and hybridization method were used as described above.

Complementation of the target gene region was performed in both the PT4 mutant strain and a representative PT11 strain. TA Cloning (Invitrogen, TOPO TA cloning kit) was used to clone the target gene region following the manufacturer's instructions. The pCR2.1 vector without insertion of target gene was also transferred into the PT4 mutant strain and the PT11 strain as a control.

\section{RESULTS}

\section{Similarities and differences in S. Enteritidis genome content}

In order to identify genetic differences between prevalent and non-prevalent/sporadic strains associated with human infection, a total of $27 \mathrm{~S}$. Enteritidis strains were tested by CGH microarray (Table 1). This included 12 strains from PT4, nine from PTs 6, 8 and 13a (prevalent PTs), and six from PT11 (non-prevalent PT). Prior to the study, the PT of all strains was reconfirmed. The genetic differences, based on the genome content of the seven Salmonella sequenced strains, showed that 3734 genes were present within all $S$. Enteritidis strains tested. This meant that 
$\sim 95 \%$ of the genome of the sequenced PT4 strain (NCTC 13349) represented on the microarray was conserved (Supplementary Table S4), and that $80 \%$ of the conserved genes were found within the core Salmonella enterica subspecies I genome, as previously described (Anjum et al., 2005), while $20 \%$ were genes from the sequenced Salmonella genomes present on the current microarray (Supplementary Table S4).

A total of 412 genes were variably present in the different $S$. Enteritidis PTs included in the study (Supplementary Table S5). This gene set was used to perform a hierarchical clustering using the Pearson correlation coefficient in GeneSpring (v7), which clustered the strains into two main groups, A and B. Group A included all strains from the prevalent PTs tested in our study and was further subdivided into PT8-like and PT4like subgroups. Group B contained only strains from non-prevalent PT11 (Fig. 1). PFGE profiles also clustered strains into the same groups and subgroups (data not shown).

\section{Group A: prevalent PTs 4, 6, 8 and 13a}

Our data showed that of all 27 strains tested from the prevalent PTs 4, 6, 8 and 13a shared more similarities to each other than to strains of the non-prevalent PT11 (Fig. 1). There were 35 genes that were present in all prevalent PT strains, but absent in all strains from nonprevalent PT11 (Table 2). More than $75 \%$ of these genes were mobile genes, including 10 plasmid genes and 18 prophage genes. The plasmid genes included a group of pefBCD (plasmid-encoded fimbriae) genes, $\operatorname{srgC}$ (SdiAregulated gene), pSLT023-026 and conjugative transfer genes pSLT075-076. Prophage genes included a degenerate Gifsy-2 prophage region (SEN0910-0912), a $12 \mathrm{~kb}$ prophage SE14 region (SEN1379-SEN1395, genome coordinates 1469682-1481286) and three genes (SEN1390 and SEN1385-1386) identified within an unknown degenerate lysogenic bacteriophage region. Seven chromosomal genes were also present exclusively in prevalent PTs. These genes were mainly located in a $4.5 \mathrm{~kb}$ region (SEN1415-1420, genome coordinates

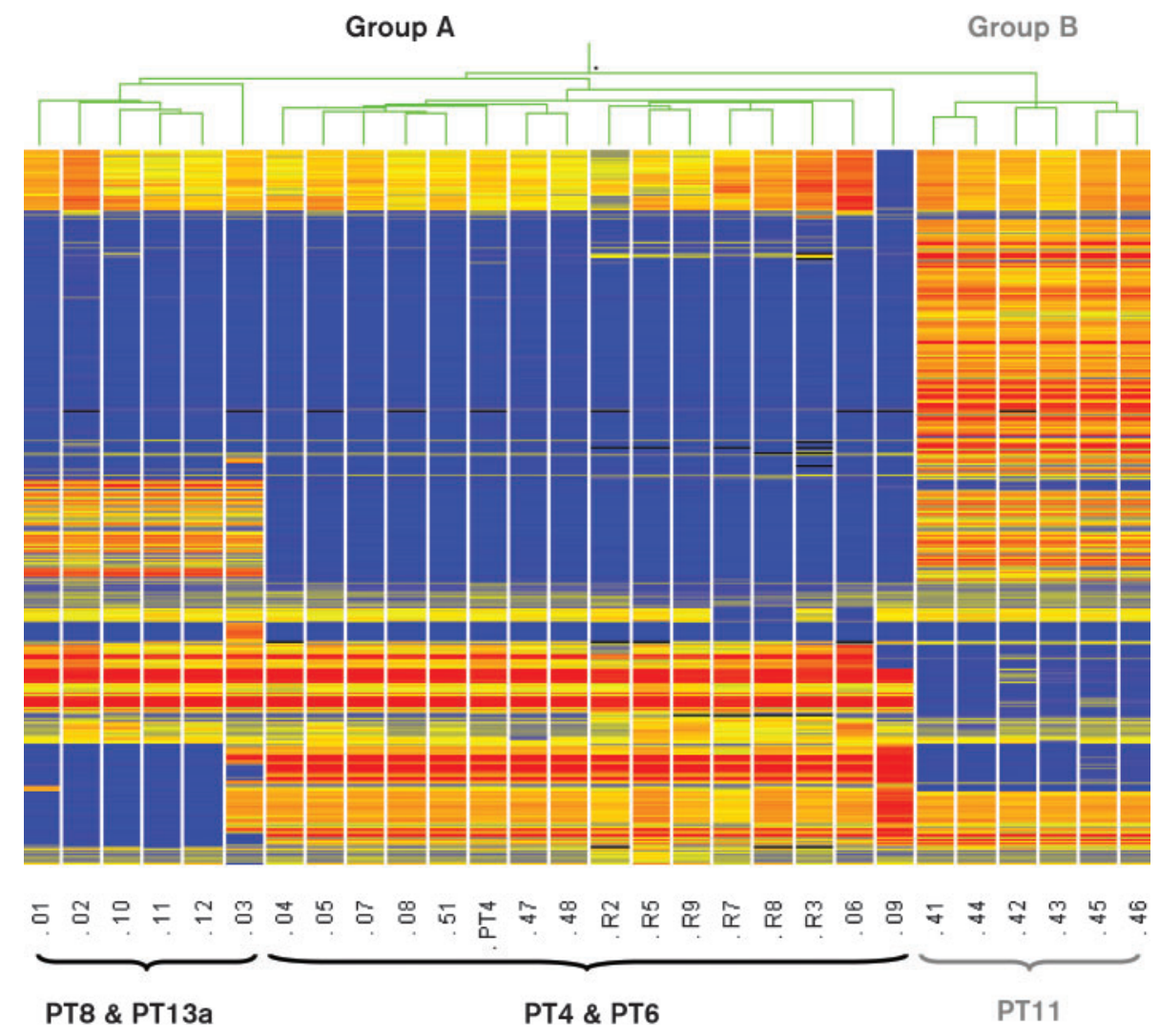

Fig. 1. Main genetic variations (412 genes) in 27 test strains representing five PTs. Two main groups were separated by genome content. The genomic relationship between strains was calculated by average-linkage hierarchical clustering using Pearson's correlation coefficient as part of the GeneSpring microarray analysis software v5.0 (Silicon Genetics). Those genes that can be considered to be absent/divergent with the greatest degree of certainty lie at the blue end of the scale, around a $\log _{10}($ Су5 : Су 3 ) ratio of 0 . Those genes that are present/conserved with the greatest degree of certainty lie in the yellow region and have a $\log _{10}($ Сy $5:$ Сy3) ratio of around 1 . The red end of the scale indicates an increased hybridization with the test strain and may be to due to the presence of genes with multiple orthologues; black represents missing data. 
Table 2. Genes identified by $\mathrm{CGH}$ microarray to be unique in prevalent PT strains

A systematic name or orthologue is given where the information is available. NA, Not available.

\begin{tabular}{|c|c|c|c|c|}
\hline Gene & Product & Prophage or plasmid, related or not & $\begin{array}{l}\text { Systematic } \\
\text { name or } \\
\text { orthologue }\end{array}$ & Notes and references \\
\hline PSLT024 & Hypothetical protein & Plasmid gene & & \\
\hline PSLT025 & Putative periplasmic protein & Plasmid gene & & \\
\hline PSLT026 & Putative cytoplasmic protein & Plasmid gene & & \\
\hline PSLTpefB & Plasmid-encoded fimbriae; regulation & Plasmid gene & PSLT019 & $\begin{array}{l}\text { The pef operon is composed of genes encoding plasmid-encoded } \\
\text { fimbriae and has been demonstrated to play an important role } \\
\text { in epithelial cell adhesion and intestinal persistence (Baumler } \\
\text { et al., 1996; van der Velden et al., 1998; Weening et al., 2005). }\end{array}$ \\
\hline PSLTpefC & Plasmid-encoded fimbriae; usher protein & Plasmid gene & PSLT017 & \\
\hline PSLTpefD & Plasmid-encoded fimbriae; chaperone & Plasmid gene & PSLT016 & \\
\hline PSLTrepA2 & DNA replication & Plasmid gene & PSLT023 & \\
\hline PSLTsrgC & SdiA-regulated gene & Plasmid gene & PSLT008 & $\begin{array}{l}\text { srg genes together with the } r c k \text { gene are downstream adjacent to } \\
\text { the pef operon, and have been reported to be regulated by SdiA, } \\
\text { which is a transcriptional regulator and recognized to be } \\
\text { involved in quorum sensing and the regulation of many } \\
\text { virulence genes (Ahmer et al., 1998). }\end{array}$ \\
\hline PSLTtraJ & Conjugative transfer: regulation & Plasmid gene & PSLT075 & \\
\hline PSLTtraY & Conjugative transfer: oriT nicking & Plasmid gene & PSLT076 & \\
\hline SEN0910 & Hypothetical protein Ent638DRAFT_3652 & Within a degenerate Gifsy-2 prophage & & \\
\hline SEN0911 & NA & Within a degenerate Gifsy-2 prophage & & \\
\hline SEN0912 & Gifsy-2 prophage probable tail fibre protein & Within a degenerate Gifsy-2 prophage & & \\
\hline SEN1379 & LygA, putative phage-encoded exoDNase & Within prophage SE14 region & & $\begin{array}{l}\text { A } 12 \mathrm{~kb} \text { region, reported to be absent from PT6a and PT35 } \\
\text { strains (Porwollik et al., 2005). }\end{array}$ \\
\hline SEN1380 & LygB, predicted phage protein & Within prophage SE14 region & & \\
\hline SEN1381 & $\begin{array}{l}\text { Putative phage-encoded cell division inhibitor } \\
\text { protein }\end{array}$ & Within prophage SE14 region & & \\
\hline SEN1382 & LygC, putative phage membrane protein & Within prophage SE14 region & & \\
\hline SEN1383 & LygD, predicted phage protein & Within prophage SE14 region & & \\
\hline SEN1388 & Predicted phage protein & Within prophage SE14 region & & \\
\hline SEN1390 & Putative bacteriophage protein & Within prophage SE14 region & & \\
\hline SEN1391 & Putative antitermination protein & Within prophage SE14 region & & \\
\hline SEN1392 & NA & Within prophage SE14 region & & \\
\hline SEN1393 & Tellurite resistance protein (E. coli) & Within prophage SE14 region & & \\
\hline SEN1394 & Putative prophage membrane protein & Within prophage SE14 region & & \\
\hline SEN1395 & Conserved phage protein & Within prophage SE14 region & & \\
\hline STY0176 & $\begin{array}{l}\text { Dihydrolipoamide acetyltransferase component } \\
\text { (E2) of pyruvate dehydrogenase }\end{array}$ & Not related & SEN0157 & \\
\hline STY1434 & Putative membrane protein & Not related & SEN1415 & \\
\hline
\end{tabular}




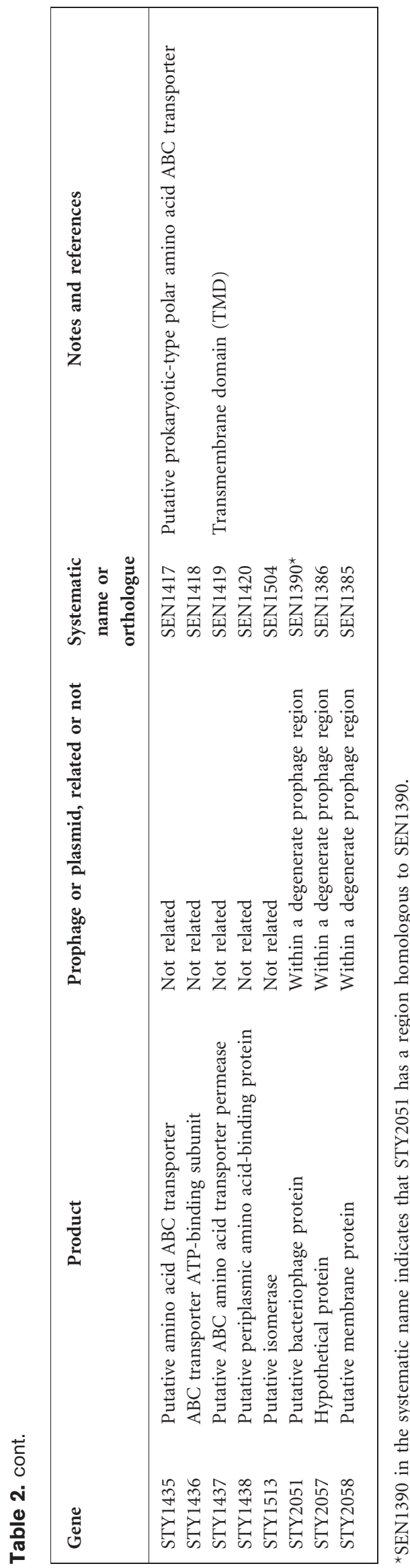

1500659-1505 193) and harbour a group of putative amino acid $\mathrm{ABC}$ transporter genes.

\section{Group B: non-prevalent PT11}

From the CGH microarray data, all strains belonging to this PT clustered together, and there were 146 genes uniquely present in PT11 strains (Fig. 1). Of these, 70 were prophagerelated genes and included genes homologous to bacteriophages ST104, P2, 186, ST64B, Gifsy-1 and Gifsy-2, and a few unknown prophage regions (Supplementary Table S6). There were also 76 non-prophage genes exclusively present in PT11 strains that included $25 \mathrm{~S}$. Typhimurium LT2 plasmid genes containing members of the tra operon (traBCEFGHTRX), ssbE and psiB, and 16 S. Typhi CT18 genes, which mainly encoded hypothetical proteins but included a ClpB-like protein (Supplementary Table S6).

\section{PCR validation}

PCR analysis was performed on a selection of genetic differences found between prevalent and non-prevalent PTs in order to validate the microarray data, and the results are listed in Supplementary Table S7. In addition to the pef genes present on the microarray ( $p e f B$, pefC, pefD and $\operatorname{srg} C$ ), the remaining genes from the pef operon (pefA, pefI) and some from the adjacent cluster ( $\operatorname{srg} A, \operatorname{srg} B$ and $r c k$ ) were also included in this analysis. PCR was also performed on the four hypothetical amino acid ABC transporter genes (SEN14171420). In order to avoid strain selection bias due to the limited number of non-prevalent PT11 strains tested on CGH microarray, another 10 PT11 strains (PE1-PE33, Table 1) of different host origin were also included. Furthermore, five strains from PTs 3,12 and 22, which are also rarely associated with human infections, were tested. PCR results for all eight genes chosen from the microarray ( $p e f B$, pefC, pefD, $\operatorname{srg} C$ and SEN1417-1420) were consistent with the microarray data, i.e. present in tested prevalent PTs but absent from all PT11 strains. However, these eight genes were found to be present in the further five strains selected from PTs 3, 12 and 22. Examination of the extra five genes showed that pefI, which is known to be a putative regulator of pef fimbrial expression (Collighan \& Woodward, 2001), and adjacent genes $\operatorname{srg} A$ and $\operatorname{srg} B$, were PCR positive for all strains from both prevalent and non-prevalent PTs. The pefA and rck genes were positive for all prevalent PT strains and the additional five strains from PT3, 12 and 22 (with exception of the $r c k$-negative PT3 strain), but negative for all PT11 stains.

\section{MLST}

In order to interpret the evolutionary relationships of different PTs, MLST was performed on seven housekeeping genes on 23 strains representing the five PTs. Our data indicated that all strains selected from the prevalent PTs 4, 6, 8 and 13a belonged to ST11, whilst all six strains from PT11 belonged to ST183. This was due to a single base pair variation in the purE locus, resulting in purE allele type 6 for strains from PTs 4, 6, 8 
and 13a, and purE allele type 60 for PT11 strains (see Supplementary Table S8). This is concordant with data from the MLST database, whereby strains of PTs 4, 6, 8, 9 and 13a belong to ST11, but PT11 strains belong to ST183.

\section{Adhesion and invasion of human epithelial cells by different PTs}

CGH microarray data highlighted significant variation in pef genes between prevalent PT strains and non-prevalent PT11 strains. This raises the question of whether adhesion and/or invasion of $S$. Enteritidis into epithelial cells is different between these groups. A panel of $18 \mathrm{~S}$. Enteritidis strains representing the five different PTs were screened in adhesion and invasion assays using human intestinal epithelial cells (Caco-2 cells). Following infection of Caco-2 cells, bacterial counts were determined and the percentage of invading bacteria with respect to the total number of adhered bacteria was calculated. The data showed that strains from all PTs invaded as well as S. Typhimurim SL1344 $(>80 \%$ of the total adhered bacteria), with the exception of PT11 strains. The PT11 strains showed significantly reduced invasion $(<75 \%$ of the total adhered bacteria) of Caco-2 cells compared with the other PTs and SL1344 $(P<0.05)$. In Fig. 2, the mean for each PT is shown, and error bars show $2 \times$ SEM to represent the $95 \%$ confidence interval within the group. Of the prevalent PTs, PT4 strains showed the highest level of invasion. Similar data were also obtained using Hep-2 cells (data not shown).

\section{Biofilm formation correlates with thin aggregative fimbriae (agf/curli) expression and colony morphology}

Of the 10 genes unique to prevalent PTs strains shown by microarray data and PCR validation, $s r g C$ and $r c k$ are both
SdiA-regulated genes. SdiA is involved in quorum sensing or biofilm formation and regulates many virulenceassociated genes (Ahmer et al., 1998). Furthermore, virulence in $S$. Enteritidis has been correlated with biofilm production, especially at low salt concentrations on abiotic surfaces (Bonafonte et al., 2000; Jain \& Chen, 2007; Korber et al., 2002; Mireles et al., 2001; Solano et al., 1998, 2001). Therefore the ability of a selection of $21 \mathrm{~S}$. Enteritidis strains to form biofilms at two different temperatures (28 and $37^{\circ} \mathrm{C}$ ) in de-salted LB medium was tested. Biofilm formation did not generally correlate with a particular PT, except for PT11 strains (Fig. 3a). Five strains were poor biofilm formers $\left(\mathrm{OD}_{570}<0.3\right)$ at both 37 and $28{ }^{\circ} \mathrm{C}$ (PT13a_1, PT13a_3, PT8_10, PT8_11 and PT4_47), whilst the rest of the 17 strains were poor biofilm formers at one temperature but moderate $\left(\mathrm{OD}_{570} 0.3-0.6\right)$ to good $\left(\mathrm{OD}_{570}\right.$ $>0.6$ ) biofilm formers at the other temperature. The PT11 strains showed the most significant increase in biofilm formation when the temperature was decreased from 37 to $28{ }^{\circ} \mathrm{C}$, whilst it was the converse in most prevalent PT strains (Fig. 3a). Expression of the thin aggregative fimbriae (agf; also called curli) is one of the key factors in biofilm formation. We detected curli expression by Congo red binding and colony morphology at 25 and $37^{\circ} \mathrm{C}$. It was noted that PT11 strains generally formed bigger and 'lacier' red colonies at both temperatures, in particular at the lower temperature, than strains from the prevalent PTs (Fig. 3b). At $37^{\circ} \mathrm{C}$, some strains from the prevalent PTs formed larger colonies, although they were generally less 'lacy' than those formed by PT11 strains (Fig. 3b).

\section{Phenotype array}

A group of amino acid transporter genes was discovered to be present in prevalent PT strains using microarray analysis

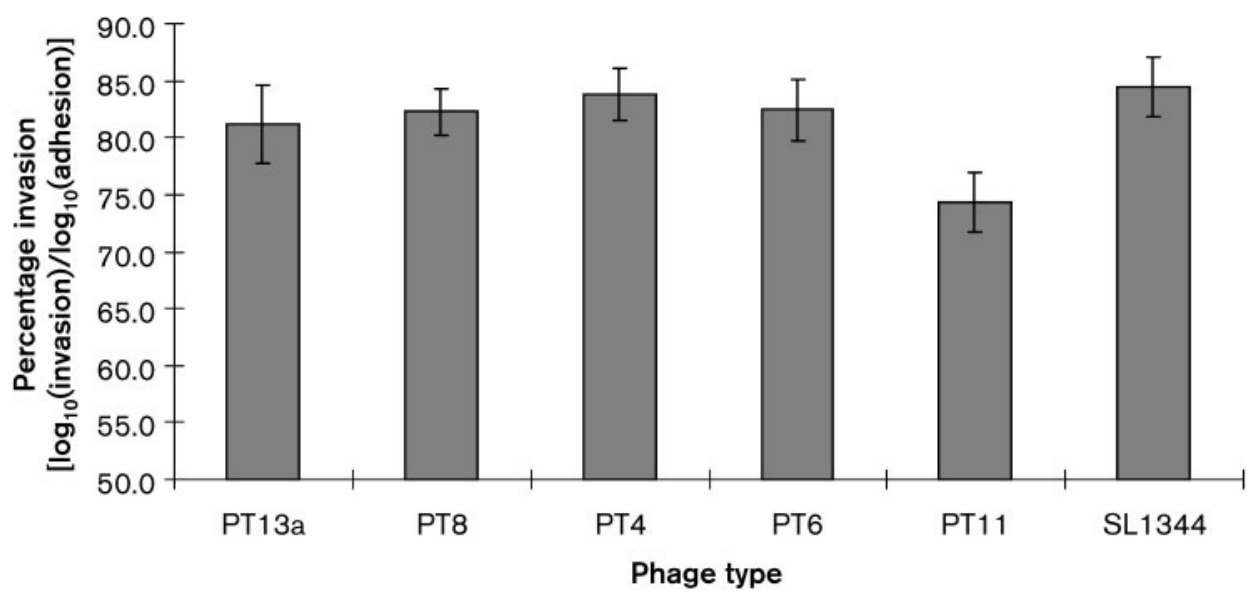

Fig. 2. S. Enteritidis association with the human adenocarcinoma cell line Caco-2 (described in Methods). The adhesion and invasion differences among five PTs from S. Enteritidis were compared. Bacterial counts were determined as described in Methods and the values shown are mean percentage invasion derived from the $\log _{10}$-transformed invasion and adhesion values. Error bars, $2 \times$ SEM. 
(a)

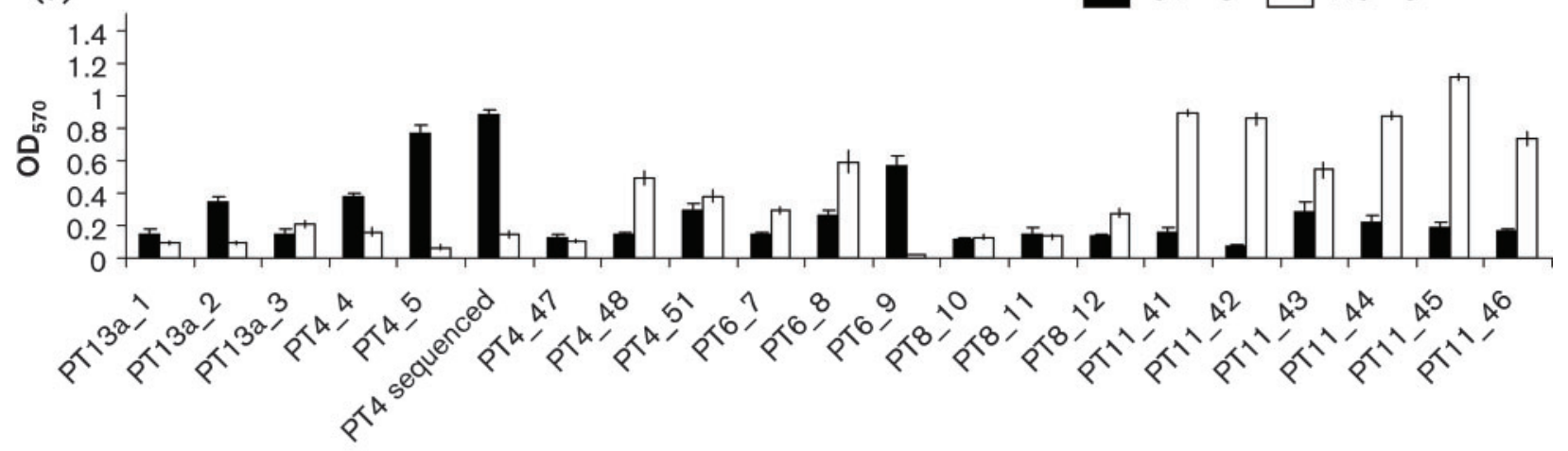

(b)

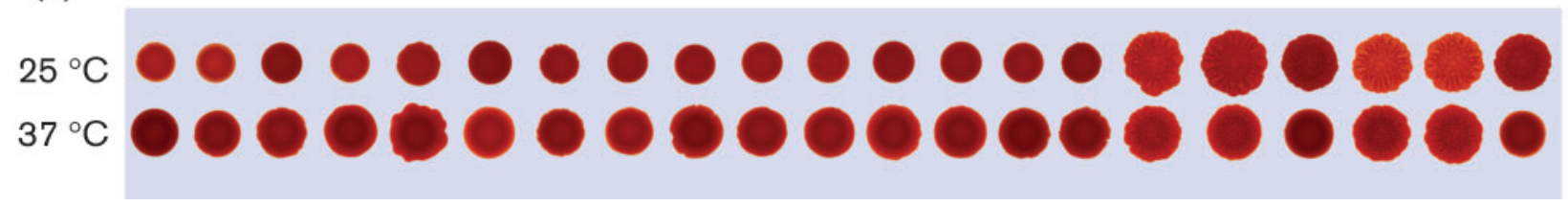

Fig. 3. (a) Comparison of the biofilm formation abilities (binding to polystyrene) of $21 \mathrm{~S}$. Enteritidis strains representing five PTs. LB-G-NaCl medium (LB medium without both glucose and sodium chloride) was used, and the incubation temperatures were 37 and $28{ }^{\circ} \mathrm{C} . \mathrm{OD}_{570}$ values were determined as described in Methods. (b) Growth of the same set of strains on CFA Congo red plates for $72 \mathrm{~h}$ at 25 and $37^{\circ} \mathrm{C}$. Colony morphology and Congo red binding abilities were compared and are displayed below the corresponding biofilm formation values.

and PCR. To determine the function of these genes in $S$. Enteritidis strains, 12 strains representative of five PTs were tested for nitrogen utilization by using Phenotype Microarray PM3 plates. Of the 95 different nitrogen substrates tested, the most outstanding differences between PT11 strains and the prevalent PT strains were in the utilization of five amino acids and two dipeptides (Table 3). Both PT11 strains clearly demonstrated a reduced ability to utilize L-histidine, L-glutamine, L- proline, L-aspartic-acid, L-cysteine, gly-asn and gly-gln compared with strains selected from the prevalent PTs, which showed good or moderate utilization of most of these substrates. Another phenotype microarray plate (PM9) was also used to test strain susceptibility to osmotic stress. Both PT11 strains were more susceptible to high concentrations of sodium chloride $(5-6 \%)$ and urea $(2-3 \%)$ than prevalent PT strains (results not shown).

Table 3. Nitrogen utilization of strains from different PTs

The nitrogen utilization of strains from different PTs was compared. Nutrient utilization, indicated by bacterial respiration, was classified as negative ( - , AUC <6000), indistinct $(+/-, 6000<$ AUC <10000) and positive $(+$, AUC $>10000)$. AUC was calculated with OmniLog-PM software.

\begin{tabular}{|c|c|c|c|c|c|c|c|c|c|c|c|c|}
\hline \multirow{2}{*}{ Substrate } & \multicolumn{2}{|c|}{ PT13a } & \multicolumn{4}{|c|}{ PT4 } & \multicolumn{2}{|c|}{ PT6 } & \multicolumn{2}{|c|}{ PT8 } & \multicolumn{2}{|c|}{ PT11 } \\
\hline & 1 & 3 & 5 & PT4 & 48 & 51 & 8 & 9 & 10 & 12 & 42 & 45 \\
\hline L-Histidine & + & + & + & + & + & + & + & + & + & + & - & - \\
\hline L-Glutamine & $+1-$ & + & + & + & + & + & + & + & + & + & - & - \\
\hline L-Proline & $+1-$ & + & + & + & + & + & + & + & + & + & - & - \\
\hline L-Aspartic acid & - & + & + & + & + & + & + & + & + & $+1-$ & - & - \\
\hline L-Cysteine & - & - & + & + & - & + & + & + & - & $+1-$ & - & - \\
\hline Gly-asn & + & + & + & + & + & + & + & + & + & + & - & - \\
\hline Gly-gln & + & + & + & + & + & + & + & + & + & + & - & - \\
\hline
\end{tabular}


(a)

PT4

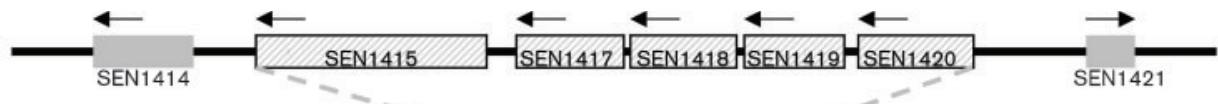

PT11

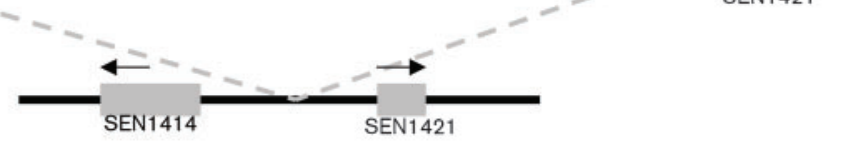

(b)

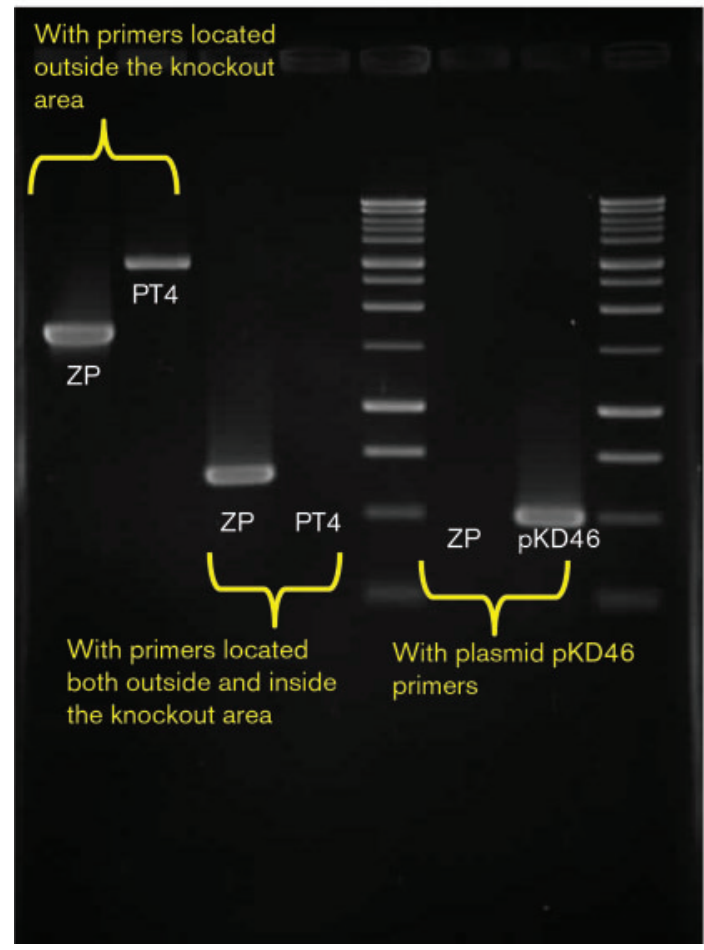

(c)

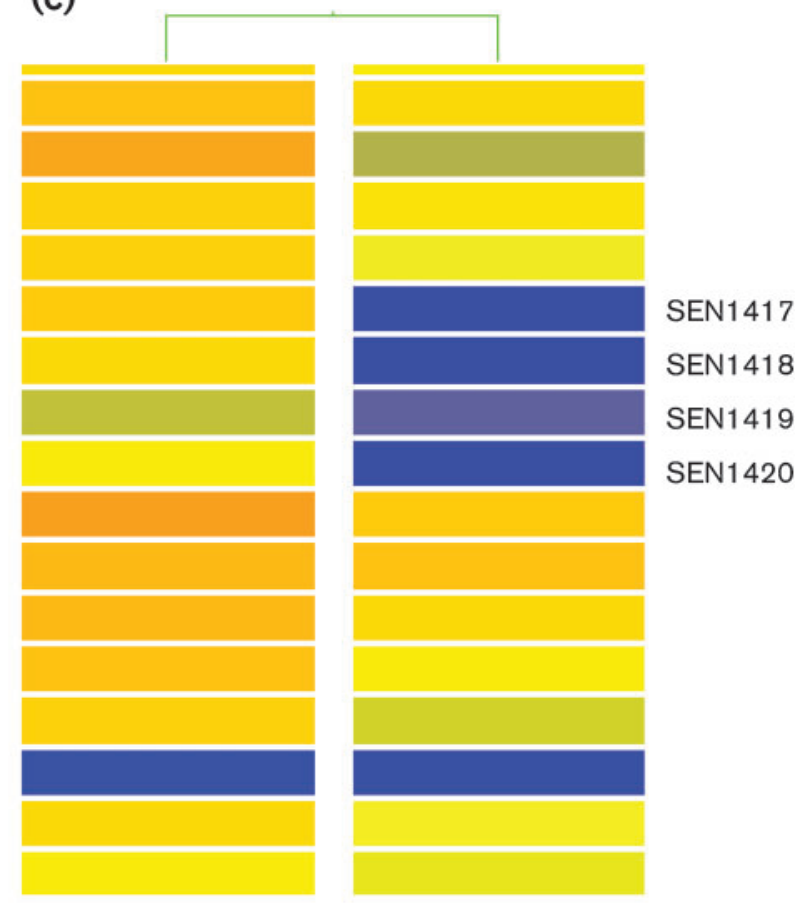

PT4

Fig. 4. (a) Comparison of the SEN1417-1420 regions in the PT4 and PT11 genomes. SEN1415-1420 are present in PT4, but absent in PT11. The SEN1417-1420 region in PT4 was disrupted by inserting a kanamycin-resistance gene. (b) PCR validation of mutant strain ZP is shown. Lanes (from left): 1 and 2, ZP and PT4 amplified with primers outside the knockout region; 3 and 4, ZP and PT4 amplified with primers outside and inside the knockout region; 5 and 8, 1 kb DNA ladders (Promega); 6 and 7, ZP and PT4 amplified with pKD46-specific primers. (c) PT4 and ZP genetic variations in the SEN14171420 region. Red/yellow indicates present genes; blue indicates absent/divergent genes.

\section{Inactivation of amino acid transporter genes and complementation}

In order to elucidate the effects of the amino acid transporter genes on amino acid utilization and osmoprotection, inactivation and complementation of the amino acid transporter genes were conducted in both PT4 and PT11 representative strains. Both PCR and microarray analysis validated the mutant, with correct insertion of the kanamycin-resistance gene (Fig. 4b) and no other rearrangement within the genome (Fig. 4c). Knockout of the SEN1417-1420 region of PT4 generated no significant effects on amino acid utilization in either the phenotype microarray or bacterial growth tests (Fig. 5a). However, complementation of these genes in a PT11 strain generated a significant increase in amino acid utilization (Fig. 5b).
Similarly, when both mutant and complemented strains were subjected to urea stress, inactivation of the amino acid transporter genes did not have a significant effect on the PT4 strain (Fig. 6a). On the other hand, the complemented PT11 strain was significantly better at coping with urea stress (Fig. 6b).

\section{DISCUSSION}

The recent epidemic caused by $S$. enterica serovar Enteritidis was not recognized until it was well established. Interventions such as vaccination of poultry, which may have been a prime factor in control, were not investigated until many years after onset. However, to intervene early requires an understanding of the basis of bacterial 
(a) Growth in $1 \mathrm{mM}$ proline minimal medium, mutation

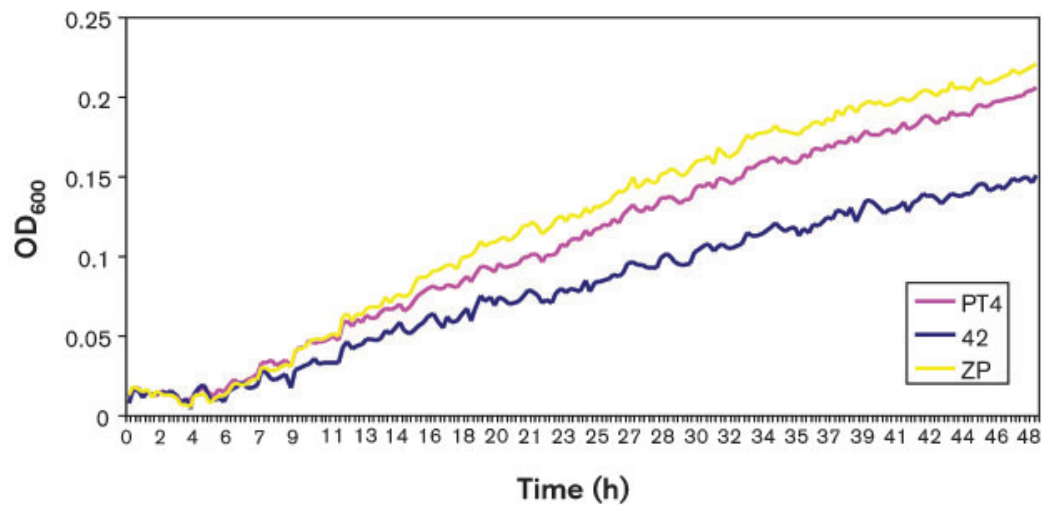

(b)

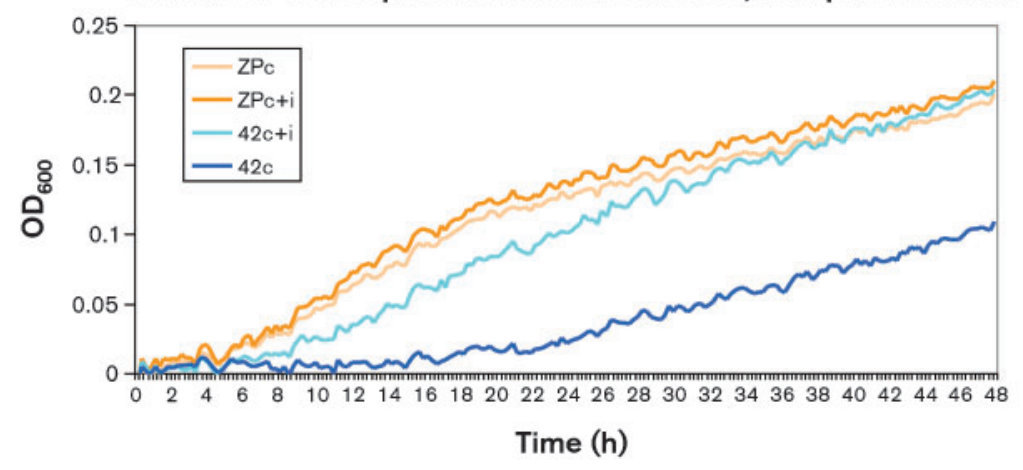

Fig. 5. Comparison of bacterial growth in $\mathrm{M} 9$ minimal medium with $1 \mathrm{mM}$ proline as both carbon and nitrogen source. (a) At least three individual repeats were performed for each strain. The AUC was calculated and Student's $t$ test was applied to validate the significance of the difference $(P=0.0003)$. PT4, PT4 sequenced strain; 42, PT11 representative strain; ZP, PT4 strain SEN1417-20::kana. (b) At least three individual repeats were performed for each strain. The AUC was calculated and Student's $t$ test was applied to validate the significance of the difference $(P=0.0086) . Z P c+i, Z P$ complemented with SEN1417-20; ZPc, ZP complemented with control plasmid without insertion; $42 \mathrm{c}+\mathrm{i}, 42$ complemented with SEN1417-20; 42c, 42 complemented with control plasmid without insertion. pathogenesis and its epidemiology. It may be argued that human epidemic strains (i.e. those highly prevalent in human infection) are 'more fit' than non-epidemic strains (i.e. those less prevalent in human infection), and therefore may carry genetic factors that enhance fitness. Therefore, the main purpose of this study was to compare genetic and other related factors of $S$. Enteritidis strains from different PTs associated with prevalent and sporadic human infections.

Most strains tested on an S. enterica CGH microarray based on seven known genomes were from human infection, although a number of strains from the most prevalent PTs were of poultry and egg origin, sources to which human infection has been attributed. Other strains from PTs 11, 3, 12 and PT22 included for PCR gene verification were of animal origin. The CGH microarray data in our study confirmed the earlier observation of Morales and Porwollik and their co-workers of genetic variations between the PT4 and PT8 groups, which are mainly in Fels-2 and ST64B, two prophage regions (Morales et al., 2005; Porwollik et al., 2005). PT11 strains in our study displayed distinct genetic properties which separated PT11 strains from both PT4 and PT8 groups, and included 70 genes in prophages ST104, P2, 186, ST64B, Gifsy-1 and Gifsy-2, and 76 nonprophage genes. Plasmid profiling (data not shown) revealed that PT11 strains possess a large plasmid $(\sim 80 \mathrm{~kb})$, whereas strains from PTs $4,6,8$ and 13a possess the virulence or spv plasmid ( $58 \mathrm{~kb})$ (Gulig et al., 1993). In addition, PFGE and MLST separated PT11 from other PTs. Collectively, these data suggest that PT11 has evolved as a unique PT lineage.

Interestingly, of the 35 genes found to be unique to strains from prevalent PTs and absent from PT11 strains, 10 plasmid genes, including pefABCD, $\operatorname{srg} C$ and pSLT023-026, were also found to be present in epidemic multi-antibioticresistant S. Typhimurium DT104 strains, but absent in non-epidemic DT208 strains (Kang et al., 2006). However, five strains from rare PTs 3, 12 and 22 were also positive for these genes in PCR validation. This suggests that other epidemicity factors play important roles in these cases. The pef genes are known to be virulence-associated, and are often involved in adhering to epithelial cells, and biofilm formation on HEp-2 cells and chicken intestinal epithelium (Baumler et al., 1996; Ledeboer et al., 2006; van der Velden et al., 1998; Weening et al., 2005). Salmonella contains at least 13 putative fimbrial operons on its chromosome, including $b c f$, sti, stf, $s a f, s t b$, fim (SEF21, type 1 fimbriae), agf (csg, SEF17, curli), stc, ste, std, lpf, sef (SEF14) and sth. Except for the plasmid-borne pef operon, all strains from both prevalent and non-prevalent PTs were found to possess these fimbrial operons. Of all fimbrial operons identified, fim, sef, agf, $l p f$ and pef have been studied most extensively. It has been demonstrated that the sef operon is expressed copiously at $37{ }^{\circ} \mathrm{C}$ and is the dominant factor in 
(a) Growth in LB-G $+3 \%$ urea, mutation

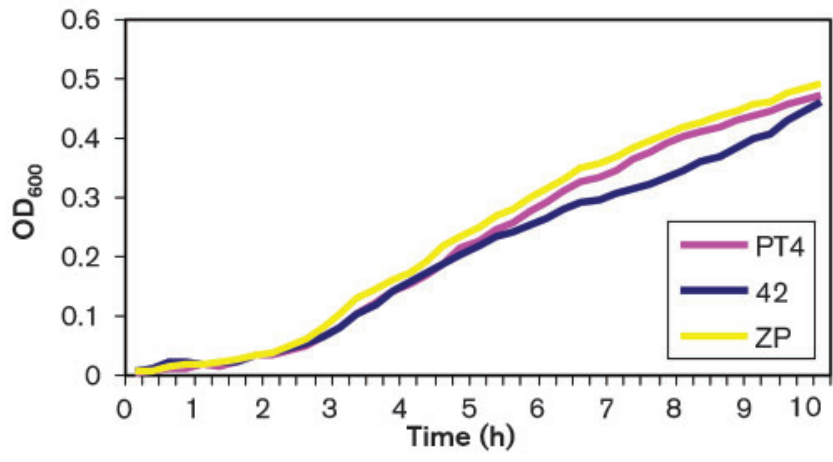

(b)

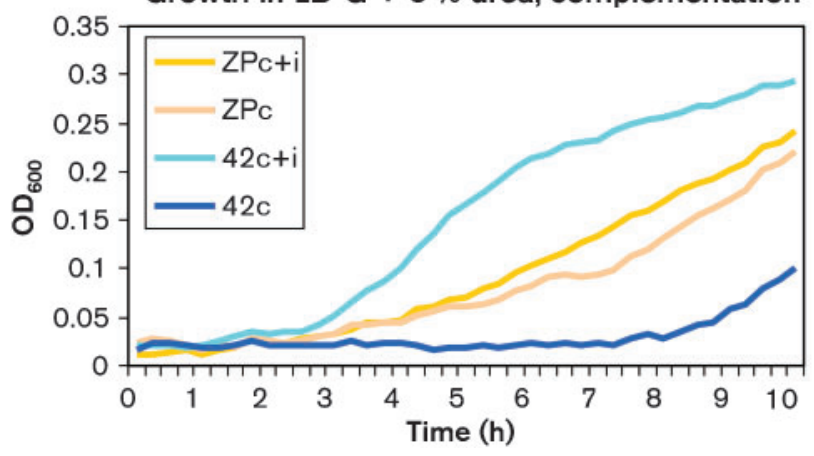

Fig. 6. Comparison of bacterial growth in LB-G medium with $3 \%$ urea. (a) At least three individual repeats were performed for each strain. The AUC was calculated and Student's $t$ test was applied to validate the significance of the difference $(P=0.014)$. PT4, PT4 sequenced strain; 42, PT11 representative strain; ZP, PT4 strain SEN1417-20::kana. (b) At least three individual repeats were performed for each strain. The AUC was calculated and Student's $t$ test was applied to validate the significance of the difference $(P=0.00025) . Z P c+\mathrm{i}, \mathrm{ZP}$ complemented with SEN1417-20; ZPc, ZP complemented with control plasmid without insertion; $42 \mathrm{c}+\mathrm{i}$, 42 complemented with SEN1417-20; 42c, 42 complemented with control plasmid without insertion.

adherence to inanimate surfaces. On the other hand, agf and fim are expressed at ambient temperature $\left(25^{\circ} \mathrm{C}\right)$, where $a g f$ is the dominant factor (Woodward et al., 2000). Interestingly, a homologue of the plasmid gene pefI (putative regulatory gene for the pef operon) has been found in the sef operon on the S. Enteritidis chromosome (Collighan \& Woodward, 2001), indicating a possible synergy in their regulation. Phenotypic characterization of our strains showed that PT11 strains were poor biofilm formers at $37{ }^{\circ} \mathrm{C}$ but had enhanced biofilm-forming ability at $25-28{ }^{\circ} \mathrm{C}$, whilst the opposite was true for most of prevalent PT strains. It is possible that the presence of pef genes in prevalent PTs enhances biofilm formation at $37{ }^{\circ} \mathrm{C}$. Another factor that probably contributes to biofilm expression at $37^{\circ} \mathrm{C}$ in the prevalent PTs is the $\operatorname{srg}$ operon. The $s r g$ operon, which includes the $r c k$ gene (resistant to complement killing) and $\operatorname{srg} A, B$ and $C$, is positively regulated by SdiA. SdiA often acts as a receptor for $\mathrm{N}$ acylhomoserine lactones (AHLs) produced by other bacteria, and plays an important role in biofilm formation and quorum sensing (Ahmer et al., 1998). Furthermore, it has been shown that expression in LB motility agar of the $r c k$ (or $s r g$ ) operon, regulated by SdiA and the presence of AHLs, is only observed at 37 and $42{ }^{\circ} \mathrm{C}$ but not at 22 and $30{ }^{\circ} \mathrm{C}$ (Smith \& Ahmer, 2003). Thus, the absence of the $r c k /$ $s r g$ operon, in conjunction with agf gene expression, likely enhances biofilm formation in PT11 strains at ambient temperature. Similarly, the increased adhesiveness and decreased invasiveness of PT11 strains of human epithelial cells at $37{ }^{\circ} \mathrm{C}$ in comparison with other PTs may be influenced by the absence of the pef and srg operons.

BLAST results for the integral membrane proteins of the identified amino acid transporter genes (SEN1417-1420) revealed that these genes encode a polar amino acid transport system. Eleven types of polar amino acid ABC transporters have been identified in bacteria (Hosie \& Poole, 2001). Nine of the 11 are solute-specific transporters, such as the histidine transporter (Nikaido et al., 1997) and the arginine transporter (Wissenbach et al., 1995). Results from the phenotype array showed that strains from the prevalent PTs, which harbour the amino acid transporter genes (SEN1417-1420), utilize at least five amino acids (L-histidine, L-glutamine, L-proline, L-aspartic-acid and L-cysteine) more effectively than PT11. This indicates that SEN1417-1420 encodes a 'broad solute specificity' amino acid transporter that can transport a wide range of acidic, basic and aliphatic L-amino acids, although these are relatively rare (Hosie \& Poole, 2001).

Proline accumulation has been shown to be an important strategy that bacteria use to cope with osmotic stress (Balaji et al., 2005; Grothe et al., 1986). The proU operon (encoding a transport system for proline and glycine betaine) promoter is induced by low water potential in Escherichia coli and Salmonella (Wright \& Beattie, 2004). Similarly, glutamate has also been shown to be necessary for S. Typhimurium to grow optimally in a highosmolarity environment (Csonka et al., 1994). We insertionally inactivated the amino acid transporter genes (SEN1417-1420) in a PT4 strain and confirmed the mutation by thorough PCR and CGH analysis. Surprisingly, the knockout mutant did not have a significant effect on amino acid utilization in PT4. However, a PT11 strain complemented with these genes showed a significant increase in proline utilization, as well as reduced susceptibility to urea stress. The different effects of these amino acid transporter genes between PT4 and PT11 strains suggest that duplication of gene functions exists in PT4, but not in PT11. The lack of functionality in PT11 strains may render PT11 strains less competitive particularly in the gastrointestinal tract and this requires further analysis. On the other hand, an extra transport system for these amino acids in prevalent PT strains is likely to contribute towards better survival under stress conditions such as in poultry faeces, an environment with a 
high urea content. Furthermore, it has been reported that the transport of amino acids or metal ions is important for S. Enteritidis to persist in egg albumin (Clavijo et al., 2006), a major route of infection in humans. Thus, the presence of the four amino acid transporter genes could allow better survival for strains from the prevalent PTs in such environments over PT11 strains. In fact the majority of animal-associated PT4 and PT6 strains isolated in the past 10 years were from poultry or eggs, whilst the majority of PT11 strains originated from a variety of hosts, with the highest numbers being from canines, rodents and hedgehogs (VLA Enteric Reference Unit). Further investigation is required to determine whether these amino acid transporter genes contribute to host adaptation and provide a selective advantage to enable PT4, PT6, PT8 and PT13a to enter the food chain to cause human salmonellosis.

\section{ACKNOWLEDGEMENTS}

We would like to thank Mrs Kathy Speed at the VLA Enteric Reference Unit and Mr Christopher Lane at the HPA Centre for Infections for database information on the $S$. Enteritidis strains; and Professor John Threlfall at the HPA for provision of the human $S$. Enteritidis strains. We would also like to thank Dr Nick Thompson at the Pathogen Sequencing Unit, Wellcome Trust Sanger Centre, for information on the annotation of several Salmonella strains included on the pan-Salmonella genome microarray. This study was funded by the UK Department for Environment, Food and Rural Affairs (Defra; OZ0324)

\section{REFERENCES}

Ahmer, B. M., van Reeuwijk, J., Timmers, C. D., Valentine, P. J. \& Heffron, F. (1998). Salmonella typhimurium encodes an SdiA homolog, a putative quorum sensor of the LuxR family, that regulates genes on the virulence plasmid. J Bacteriol 180, 1185-1193.

Allen-Vercoe, E., Dibb-Fuller, M., Thorns, C. J. \& Woodward, M. J. (1997). SEF17 fimbriae are essential for the convoluted colonial morphology of Salmonella enteritidis. FEMS Microbiol Lett 153, 3342.

Anjum, M. F., Marooney, C., Fookes, M., Baker, S., Dougan, G., Ivens, A. \& Woodward, M. J. (2005). Identification of core and variable components of the Salmonella enterica subspecies I genome by microarray. Infect Immun 73, 7894-7905.

Balaji, B., O’Connor, K., Lucas, J. R., Anderson, J. M. \& Csonka, L. N. (2005). Timing of induction of osmotically controlled genes in Salmonella enterica serovar Typhimurium, determined with quantitative real-time reverse transcription-PCR. Appl Environ Microbiol 71, 8273-8283.

Baumler, A. J., Tsolis, R. M., Bowe, F. A., Kusters, J. G., Hoffmann, S. \& Heffron, F. (1996). The pef fimbrial operon of Salmonella typhimurium mediates adhesion to murine small intestine and is necessary for fluid accumulation in the infant mouse. Infect Immun 64, 61-68.

Baumler, A. J., Hargis, B. M. \& Tsolis, R. M. (2000). Tracing the origins of Salmonella outbreaks. Science 287, 50-52.

Boccia, D., Oliver, C. I., Charlett, A., Bennett, S., Orr, H., Sarangi, J. \& Stuart, J. (2004). Outbreak of a new Salmonella phage type in South West England: alternative epidemiological investigations are needed. Commun Dis Public Health 7, 339-343.
Bolton, A. J., Osborne, M. P. \& Stephen, J. (2000). Comparative study of the invasiveness of Salmonella serotypes Typhimurium, Choleraesuis and Dublin for Caco-2 cells, HEp-2 cells and rabbit ileal epithelia. J Med Microbiol 49, 503-511.

Bonafonte, M. A., Solano, C., Sesma, B., Alvarez, M., Montuenga, L., Garcia-Ros, D. \& Gamazo, C. (2000). The relationship between glycogen synthesis, biofilm formation and virulence in Salmonella enteritidis. FEMS Microbiol Lett 191, 31-36.

Brown, D. J., Baggesen, D. L., Platt, D. J. \& Olsen, J. E. (1999). Phage type conversion in Salmonella enterica serotype Enteritidis caused by the introduction of a resistance plasmid of incompatibility group X (IncX). Epidemiol Infect 122, 19-22.

Carter, B., Wu, G., Woodward, M. J. \& Anjum, M. F. (2008). A process for analysis of microarray comparative genomics hybridisation studies for bacterial genomes. BMC Genomics 9, 53.

Clavijo, R. I., Loui, C., Andersen, G. L., Riley, L. W. \& Lu, S. (2006). Identification of genes associated with survival of Salmonella enterica serovar Enteritidis in chicken egg albumen. Appl Environ Microbiol 72, 1055-1064.

Collighan, R. J. \& Woodward, M. J. (2001). The SEF14 fimbrial antigen of Salmonella enterica serovar Enteritidis is encoded within a pathogenicity islet. Vet Microbiol 80, 235-245.

Cooke, F. J., Wain, J., Fookes, M., Ivens, A., Thomson, N., Brown, D. J., Threlfall, E. J., Gunn, G., Foster, G. \& Dougan, G. (2007). Prophage sequences defining hot spots of genome variation in Salmonella enterica serovar Typhimurium can be used to discriminate between field isolates. J Clin Microbiol 45, 2590-2598.

Csonka, L. N., Ikeda, T. P., Fletcher, S. A. \& Kustu, S. (1994). The accumulation of glutamate is necessary for optimal growth of Salmonella typhimurium in media of high osmolality but not induction of the proU operon. J Bacteriol 176, 6324-6333.

Datsenko, K. A. \& Wanner, B. L. (2000). One-step inactivation of chromosomal genes in Escherichia coli K-12 using PCR products. Proc Natl Acad Sci U S A 97, 6640-6645.

Dibb-Fuller, M. P., Allen-Vercoe, E., Thorns, C. J. \& Woodward, M. J. (1999). Fimbriae- and flagella-mediated association with and invasion of cultured epithelial cells by Salmonella enteritidis. Microbiology 145, 1023-1031.

Echeita, M. A., Aladuena, A. M., Diez, R., Arroyo, M., Cerdan, F., Gutierrez, R., de la Fuente, M., Gonzalez-Sanz, R., Herrera-Leon, S. \& Usera, M. A. (2005). Serotype and phage type distribution of human Salmonella strains isolated in Spain, 1997-2001. Enferm Infecc Microbiol Clin 23, 127-134.

European Food Safety Authority (2008). The Community Summary Report on Trends and Sources of Zoonoses and Zoonotic Agents in the European Union in 2007. http://www.efsa.europa.eu/EFSA/efsa_locale1178620753812_1211902269834.htm

Gatto, A. J., Peters, T. M., Green, J., Fisher, I. S., Gill, O. N., O’Brien, S. J., Maguire, C., Berghold, C., Lederer, I. \& other authors (2006). Distribution of molecular subtypes within Salmonella enterica serotype Enteritidis phage type 4 and S. Typhimurium definitive phage type 104 in nine European countries, 2000-2004: results of an international multi-centre study. Epidemiol Infect 134, 729-736.

Gillespie, I. A., O’Brien, S. J., Adak, G. K., Ward, L. R. \& Smith, H. R. (2005). Foodborne general outbreaks of Salmonella Enteritidis phage type 4 infection, England and Wales, 1992-2002: where are the risks? Epidemiol Infect 133, 795-801.

Grothe, S., Krogsrud, R. L., McClellan, D. J., Milner, J. L. \& Wood, J. M. (1986). Proline transport and osmotic stress response in Escherichia coli K-12. J Bacteriol 166, 253-259.

Guard-Petter, J. (1999). Phage type and other outer-membrane characteristics of Salmonella enterica serovar Enteritidis associated 
with virulence. In Salmonella Enterica Serovar Enteritidis in Humans and Animals (Epidemiology, Pathogenesis and Control), pp. 221-232. Edited by R. K. Gast, A. M. Saeed, M. E. Potter \& P. G. Wall. Ames, IA: Iowa State University Press.

Gulig, P. A., Danbara, H., Guiney, D. G., Lax, A. J., Norel, F. \& Rhen, M. (1993). Molecular analysis of $s p v$ virulence genes of the Salmonella virulence plasmids. Mol Microbiol 7, 825-830.

Hosie, A. H. \& Poole, P. S. (2001). Bacterial ABC transporters of amino acids. Res Microbiol 152, 259-270.

Jain, S. \& Chen, J. (2007). Attachment and biofilm formation by various serotypes of Salmonella as influenced by cellulose production and thin aggregative fimbriae biosynthesis. J Food Prot 70, 2473-2479.

Kang, M. S., Besser, T. E., Hancock, D. D., Porwollik, S., McClelland, M. \& Call, D. R. (2006). Identification of specific gene sequences conserved in contemporary epidemic strains of Salmonella enterica. Appl Environ Microbiol 72, 6938-6947.

Korber, D. R., Greer, G. G., Wolfaardt, G. M. \& Kohlman, S. (2002). Efficacy enhancement of trisodium phosphate against spoilage and pathogenic bacteria in model biofilms and on adipose tissue. J Food Prot 65, 627-635.

Ledeboer, N. A., Frye, J. G., McClelland, M. \& Jones, B. D. (2006). Salmonella enterica serovar Typhimurium requires the Lpf, Pef, and Tafi fimbriae for biofilm formation on HEp-2 tissue culture cells and chicken intestinal epithelium. Infect Immun 74, 3156-3169.

Lukinmaa, S., Nakari, U. M., Liimatainen, A. \& Siitonen, A. (2006). Genomic diversity within phage types of Salmonella enterica ssp. enterica serotypes Enteritidis and Typhimurium. Foodborne Pathog Dis 3, 97-105.

Mireles, J. R., II, Toguchi, A. \& Harshey, R. M. (2001). Salmonella enterica serovar Typhimurium swarming mutants with altered biofilm-forming abilities: surfactin inhibits biofilm formation. J Bacteriol 183, 5848-5854.

Morales, C. A., Porwollik, S., Frye, J. G., Kinde, H., McClelland, M. \& Guard-Bouldin, J. (2005). Correlation of phenotype with the genotype of egg-contaminating Salmonella enterica serovar Enteritidis. Appl Environ Microbiol 71, 4388-4399.

Nikaido, K., Liu, P. Q. \& Ames, G. F. (1997). Purification and characterization of HisP, the ATP-binding subunit of a traffic ATPase (ABC transporter), the histidine permease of Salmonella typhimurium. Solubility, dimerization, and ATPase activity. J Biol Chem 272, 27745-27752.

Porwollik, S., Santiviago, C. A., Cheng, P., Florea, L. \& McClelland, M. (2005). Differences in gene content between Salmonella enterica serovar Enteritidis isolates and comparison to closely related serovars Gallinarum and Dublin. J Bacteriol 187, 6545-6555.

Rodrigue, D. C., Tauxe, R. V. \& Rowe, B. (1990). International increase in Salmonella enteritidis: a new pandemic? Epidemiol Infect $105,21-27$.

Smith, J. N. \& Ahmer, B. M. (2003). Detection of other microbial species by Salmonella: expression of the SdiA regulon. J Bacteriol 185 , 1357-1366.
Solano, C., Sesma, B., Alvarez, M., Humphrey, T. J., Thorns, C. J. \& Gamazo, C. (1998). Discrimination of strains of Salmonella enteritidis with differing levels of virulence by an in vitro glass adherence test. $J$ Clin Microbiol 36, 674-678.

Solano, C., Sesma, B., Alvarez, M., Urdaneta, E., Garcia-Ros, D., Calvo, A. \& Gamazo, C. (2001). Virulent strains of Salmonella enteritidis disrupt the epithelial barrier of Caco-2 and HEp-2 cells. Arch Microbiol 175, 46-51.

Thomson, N., Baker, S., Pickard, D., Fookes, M., Anjum, M., Hamlin, N., Wain, J., House, D., Bhutta, Z. \& other authors (2004). The role of prophage-like elements in the diversity of Salmonella enterica serovars. J Mol Biol 339, 279-300.

Usera, M. A., Popovic, T., Bopp, C. A. \& Strockbine, N. A. (1994). Molecular subtyping of Salmonella enteritidis phage type 8 strains from the United States. J Clin Microbiol 32, 194-198.

van der Velden, A. W., Baumler, A. J., Tsolis, R. M. \& Heffron, F. (1998). Multiple fimbrial adhesins are required for full virulence of Salmonella typhimurium in mice. Infect Immun 66, 2803-2808.

Ward, L. R., de Sa, J. D. \& Rowe, B. (1987). A phage-typing scheme for Salmonella enteritidis. Epidemiol Infect 99, 291-294.

Ward, L. R., Threlfall, J., Smith, H. R. \& O’Brien, S. J. (2000). Salmonella enteritidis epidemic. Science 287, 1753-1754.

Weening, E. H., Barker, J. D., Laarakker, M. C., Humphries, A. D., Tsolis, R. M. \& Baumler, A. J. (2005). The Salmonella enterica serotype Typhimurium $l p f, b c f, s t b, s t c, s t d$, and $s t h$ fimbrial operons are required for intestinal persistence in mice. Infect Immun 73, 33583366.

White, P. L., Naugle, A. L., Jackson, C. R., Fedorka-Cray, P. J., Rose, B. E., Pritchard, K. M., Levine, P., Saini, P. K., Schroeder, C. M. \& other authors (2007). Salmonella enteritidis in meat, poultry, and pasteurized egg products regulated by the U.S. Food Safety and Inspection Service, 1998 through 2003. J Food Prot 70, 582-591.

Wissenbach, U., Six, S., Bongaerts, J., Ternes, D., Steinwachs, S. \& Unden, G. (1995). A third periplasmic transport system for L-arginine in Escherichia coli: molecular characterization of the artPIQMJ genes, arginine binding and transport. Mol Microbiol 17, 675-686.

Woodward, M. J., Sojka, M., Sprigings, K. A. \& Humphrey, T. J. (2000). The role of SEF14 and SEF17 fimbriae in the adherence of Salmonella enterica serotype Enteritidis to inanimate surfaces. J Med Microbiol 49, 481-487.

Wright, C. A. \& Beattie, G. A. (2004). Bacterial species specificity in proU osmoinducibility and $n p t I I$ and lacZ expression. J Mol Microbiol Biotechnol 8, 201-208.

Wu, G., Carter, B., Mafura, M., Liebana, E., Woodward, M. J. \& Anjum, M. F. (2008). Genetic diversity among Escherichia coli O157:H7 isolates and identification of genes linked to human infections. Infect Immun 76, 845-856.

Edited by: M. P. Stevens 